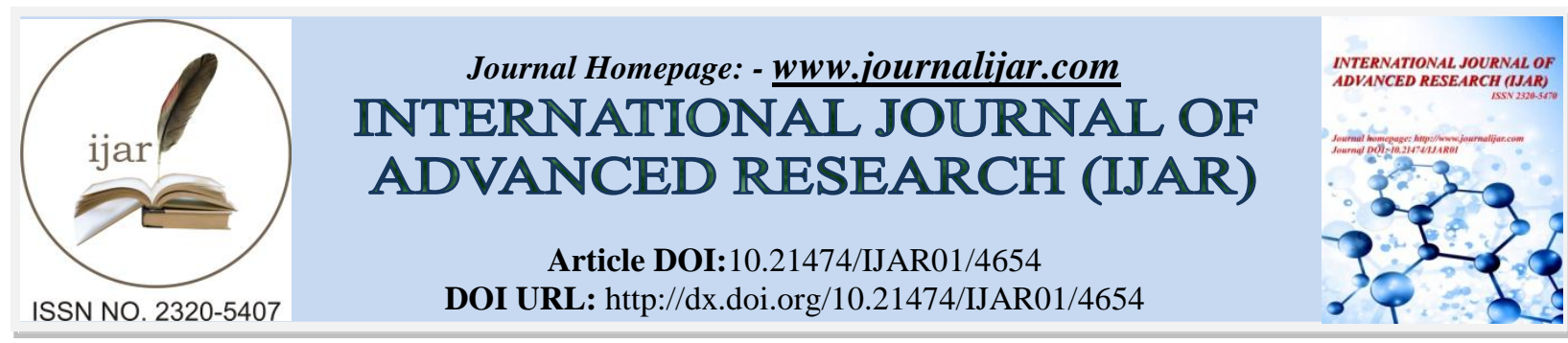

RESEARCH ARTICLE

\title{
ROLE OF MOBILE/PHONE TEXT MESSAGING (SMS) FOR PROVIDING ORAL HEALTH EDUCATION TO MOTHERS OF PRIMARY SCHOOL CHILDREN IN MANGALORE CITY: A RANDOMIZED CONTROLLED TRIAL.
}

\author{
Dr. Richa Gupta ${ }^{1}$, Dr. Rajesh G ${ }^{2}$, Dr. Ashwini Rao $^{3}$ and Dr. Ramya Shenoy ${ }^{4}$. \\ 1. PG student, Department of Public Health Dentistry, Manipal College of Dental Sciences, Mangalore - 575001, \\ Manipal University, Karnataka, india. \\ 2. Professor and Head Department of Public Health Dentistry, Manipal College of Dental Sciences, Mangalore - \\ 575001, Manipal University, Karnataka, india. \\ 3. Professor, Department of Public Health Dentistry Manipal College of Dental Sciences, Mangalore - 575001, \\ Manipal University, Karnataka, india. \\ 4. Associate Professor, Department of Public Health Dentistry Manipal College of Dental Sciences, Mangalore - \\ 575001, Manipal University, Karnataka, india.
}

\section{Manuscript Info}

\section{Manuscript History}

Received: 24 April 2017

Final Accepted: 28 May 2017

Published: June 2017

Key words:-

Technology, health education, oral health.

\section{Abstract}

Background:- Advances in information technology has changed lifestyles of people all over the world. Exploring various possibilities that employ technology for disseminating preventive information to the community is crucial. Objectives: To determine and compare the effects of phone text messaging (SMS), e-mail messaging, and pamphlets on oral health knowledge and attitude of the mothers of primary school children in Mangalore city. Methods: A randomized control trial design was employed. Overall, 220 primary school students were selected by stratified random sampling and were randomly allocated to 4 groups: Phone text messaging (SMS), e-mail messaging, pamphlets and control. Oral health education was delivered every week during the intervention period. Oral health knowledge and attitude of mother was assessed pre and post intervention by questionnaire. Subjects were followed for a period of 6 months. Results: Final knowledge scores for groups I-IV were $8.8 \pm 1.54,7.1 \pm 1.84,9.3 \pm 1.50$ and $4.3 \pm 1.81$ respectively. Final awareness scores for groups I-IV were $8.8 \pm 1.4,7.6 \pm 1.37,7.5 \pm 1.63$ and $4.9 \pm 2.06$ respectively. There were significant improvements in knowledge and attitude scores in phone (SMS), e-mail and pamphlet group $(\mathrm{p}<0.05)$. Pamphlet group was better than mobile and email groups in improving behavior scores $(\mathrm{p}<0.05)$. Mobile group was significantly better than e-mail and pamphlets $(\mathrm{p}<0.05)$ in improving the attitude scores. Conclusion: SMS messages by phones was effective in improving the attitudes of study subject. Text messaging has the potential to reach large number of individuals at relatively low cost and may be cost effective when compared with conventional methods. 


\section{Introduction:-}

Dental caries remains the most important dental health problem in developing countries; prevalence of which is reported to be 50-60\% in India (Patro et al., 2013). It is a major oral health problem in developing countries, affecting $60-90 \%$ of the school children. Traditional curative dental care is a significant economic burden for many high-income countries, where 5-10\% of public health expenditure relates to oral health. In low- and middle-income countries, public oral health programmes are not very frequent. The high cost of dental treatment can be avoided by effective prevention and health promotion measures (Nakre and Harikiran, 2013).

Health education is a significant aspect of health promotion and knowledge about health and its determinants is important for the maintenance of health, and ignorance regarding the same can be dis-empowering. The provision of health-related information to individuals and policy makers is now accepted as an important part of health promotion (WHO, 2014).

Schools can be an important setting for health education programmes, controlling the growing burden of oral diseases and promoting oral health (Yazdani et al., 2009). It is a setting where education and health programmes can have their greatest impact because they influence students at such important stages in their lives - childhood and adolescence (WHO, 2000). Schools can also provide an important network and channel to the local community. Health promotion activities can be targeted at the home and throughout the community by school personnel. Similarly, through the pupils, health promotion messages can be passed on to other members of the family (Booth and Samdal, 1997).

Boom in information technology and computer sciences have changed the life style quotient of people. The key factor of patient communication has been also made easy with new advances (Balappanavar et al., 2013). Web pages and other information-gathering devices have become an essential part of our daily life, as they provide extensive information on all aspects of our society. This is mirrored in dental education where there are many different tools available (Mattheos et al., 2008).

In a country like India, with limited resources and manpower, community based methods and methods directed towards school children are feasible and cost effective means to prevent rising trend of oral diseases. Exploring the possibilities in the usage of technology for disseminating the preventive information to the community is becoming the latest trend. In view of dearth of resources and from the public health point of view, an imperative need arises to know which method of dental health education is more effective(Rajesh et al, 2008).

Earlier studies have reported the feasibility of using SMS messages for oral health education (Sharma et al, 2011; Hashemian et al, 2015). With these factsheet in mind, this study was undertaken to compare the various methods of communication for the delivery of the oral health education program. The aim of the present study was to determine the influence of mobile phone text messaging (SMS) for providing oral health education to mothers of primary school children in Mangalore city.

\section{Methodology:-}

\section{Study Design and Sampling:-}

The present study was employed a cluster, randomized controlled trial design. Primary school children without previous history of oral health education and intervention were included. Participants who have undergone or are undergoing treatment for any systematic disease or condition and differently abled children will be excluded. A pilot study was conducted among 30 adults, and a minimum sample size of 150 was calculated by Altman's normogram for the present study. The list of all the schools in Mangalore was obtained from the Block Education officer (Enclosure 4) and five schools from different zones, which were similar in socio-economic status and standard of teaching, were randomly selected by simple random sampling using the table of random numbers. Permission to conduct the study at schools was obtained from the principals of respective schools (Enclosure 1, 2, 3,)

\section{Ethical Considerations:-}

Institutional Ethics committee (IEC) approval was obtained for the present study (Protocol number - 14119) (Annexures 5). Informed consent was obtained from parents of the school children. (Annexures 4). 


\section{Summary of the Questionnaire:-}

Participant's oral health knowledge and attitude were assessed by administering a self-administered questionnaire to the study participants. Prior to the start of the main study, the questionnaires were administered to 35 study participants. Reliability of the questionnaire was assessed by employing Cronbach's alpha. The assessment of reliability for the knowledge and attitude. Scores showed there was good internal consistency (Cronbach's alpha for knowledge and attitude were 0.82 and 0.84 ) (Annexure 2).

\section{Details of Intervention:-}

Over all 360 students from 3 schools consented to participate in the randomized control trial. After the groups were balanced for oral health Knowledge and attitude, 290 students were randomized into the study groups. To avoid dissemination of information given to the participants the schools were randomly allocated to four different methods, which were: (group I-IV): mobile phone text messaging (SMS), e-mail messaging and pamphlet and control respectively. In the control group, conventional oral health education was provided without any aids. A total of three reinforcements of oral health education were provided at one, two and three months for all the study groups.

\section{Evaluation of Intervention:-}

The final assessment was carried out after a period of six months after the oral health education. Intervention was evaluated by administering the same questionnaire to all the groups and assessing improvements in oral healthrelated knowledge and attitude (correct answers).

\section{Statistical Analysis:-}

The Statistical Package for Social Sciences (SPSS), version 16 (SPSS Inc, Chicago IL). Was used to analyze the dat. Level of significance was fixed at $95 \%$ level $(\mathrm{p}<0.05)$. Paired t-test was used to find the significance between the groups before and after intervention. Analysis of variance (ANOVA) has been used to find the significance of study parameters (oral hygiene knowledge and attitude) between the four groups. Repeated -measures ANOVA has been used to find the significance of oral hygiene knowledge and attitudes scores at baseline and 6 months.

\section{Results:-}

A total of 270 (out of 290) preschool children and their mothers completed the study. The mobile group comprised 72 children, the e-mail group comprised 71 children, pamphlet group comprised 69 children and control group comprised 72 children. [Table 1]

Baseline oral health knowledge scores were found to be $2.9 \pm 1.59,5.9 \pm 1.58,7.8 \pm 1.63$ and $2.7 \pm 1.68$ in groups I-IV respectively. Final knowledge scores for groups I-IV were $8.8 \pm 1.54,7.1 \pm 1.84,9.3 \pm 1.50$ and $4.3 \pm 1.81$ respectively [Table 2]. Baseline oral health attitude scores were found to be $3.2 \pm 1.5,2.1 \pm 1.4,5.1 \pm 1.7$ and $2.8 \pm 1.7$ for groups IIV respectively. Final awareness scores for groups I-IV were $8.8 \pm 1.4,7.6 \pm 1.37,7.5 \pm 1.63$ and $4.9 \pm 2.06$ respectively [Table 3].

Intergroup comparison of baseline and follow up oral health related knowledge and attitude scores revealed a statistically significant differences between groups at the end of the study period $(\mathrm{p}<0.05)$ [Table 4]. Intergroup analysis revealed that there were statistically significant differences in oral health knowledge scores between group I and II and between I and III ( $\mathrm{p}<0.05)$. There were significant differences in knowledge scores between groups II and III, II and IV and between III and IV $(p<0.05)$. There were no significant differences in knowledge scores between I and IV at the end of the study period ( $p>0.05$ ) [Table 5]. Intergroup analysis revealed that there were statistically significant differences in oral health attitude scores between group I and II, between I and III, and I and IV ( $\mathrm{p}<0.05$ ). There were significant differences in attitude scores between groups II and III, II and IV and between III and IV at the end of the study period $(\mathrm{p}<0.05)$ [Table 6].

Table 1:- Distribution of study participants .

\begin{tabular}{|c|c|c|c|}
\hline $\begin{array}{c}\text { Groups (method of } \\
\text { Health education) }\end{array}$ & $\begin{array}{c}\text { No. of Students in the } \\
\text { beginning of the study }\end{array}$ & $\begin{array}{c}\text { No. of students in the end } \\
\text { of the study }\end{array}$ & Attrition \\
\hline Mobile & 74 & 72 & 2 \\
\hline e-mail & 71 & 63 & 8 \\
\hline Pamphlet & 69 & 69 & 0 \\
\hline Control & 76 & 72 & 4 \\
\hline Total & 290 & 270 & 14 \\
\hline
\end{tabular}


Table 2:- Mean knowledge scores at baseline at follow up and change in mean knowledge scores in various groups.

\begin{tabular}{|l|c|c|c|c|}
\hline \multirow{2}{*}{$\begin{array}{l}\text { Group (method of Health } \\
\text { education) }\end{array}$} & Mean & $\begin{array}{c}\text { Standard } \\
\text { Deviation }\end{array}$ & Mean & $\begin{array}{c}\text { Standard } \\
\text { Deviation }\end{array}$ \\
\cline { 2 - 5 } & 2.9 & 1.59 & 8.8 & 1.54 \\
\hline Mobile & 5.9 & 1.58 & 7.1 & 1.84 \\
\hline e-mail & 7.8 & 1.63 & 9.3 & 1.50 \\
\hline Pamphlet & 2.7 & 1.68 & 4.3 & 1.81 \\
\hline
\end{tabular}

Table 3:-Mean attitude scores at baseline at follow up and change in mean attitude scores in various groups.

\begin{tabular}{|l|c|c|c|c|}
\hline \multirow{2}{*}{ Group (method of Health education) } & \multicolumn{2}{|c|}{ Baseline } & \multicolumn{2}{|c|}{ Follow-up } \\
\cline { 2 - 5 } & Mean & $\begin{array}{c}\text { Standard Deviation } \\
(\mathbf{\pm})\end{array}$ & $\begin{array}{c}\text { Mean } \\
\text { Standard Deviation } \\
( \pm)\end{array}$ \\
\hline Mobile & 3.2 & 1.5 & 8.8 & 1.4 \\
\hline e-mail & 2.1 & 1.4 & 7.6 & 1.37 \\
\hline Pamphlet & 5.1 & 1.7 & 7.5 & 1.63 \\
\hline Control & 2.8 & 1.7 & 4.9 & 2.06 \\
\hline
\end{tabular}

Table 4:-Intergroup comparison of baseline and follow up oral health related knowledge and attitude scores.

\begin{tabular}{|l|c|c|c|c|}
\hline $\begin{array}{l}\text { Variable } \\
\text { (Mean Difference) }\end{array}$ & Degree of Freedom & Mean square & F value & p value \\
\hline Knowledge & 3 & 552.05 & 207.28 & $0.00^{*}$ \\
\hline Attitude & 3 & 286.82 & 117.69 & $0.00^{*}$ \\
\hline
\end{tabular}

$* \mathrm{p}$ value $(<0.05=$ significant $)$

Table 5:-Intergroup comparison (post hoc analysis) of follow up oral health Knowledge.

\begin{tabular}{|c|c|c|c|c|c|c|}
\hline \multirow{2}{*}{ Groups } & \multicolumn{3}{|c|}{ Mean difference } & P value & Minimum & Maximum \\
\cline { 2 - 6 } & $\begin{array}{c}\text { Group 1 } \\
\text { (Mobile) }\end{array}$ & $\begin{array}{c}\text { Group 2 } \\
\text { (e- mail) }\end{array}$ & $\begin{array}{c}\text { Group 3 } \\
\text { (Pamphlet) }\end{array}$ & & & \\
\hline $\begin{array}{c}\text { Group 1 } \\
\text { (Mobile) }\end{array}$ & & 2.97 & & $0.30^{*}$ & -1.2 & 0.49 \\
\hline $\begin{array}{c}\text { Group 1 } \\
\text { (Mobile) }\end{array}$ & & 6.41 & $0.00^{*}$ & -3.6 & 2.4 \\
\hline $\begin{array}{c}\text { Group 2 } \\
\text { (e-mail) }\end{array}$ & & 2.43 & $0.00^{*}$ & -3.0 & 1.8 \\
\hline $\begin{array}{c}\text { Group 4 } \\
\text { (control) }\end{array}$ & $\mathbf{0 . 3 3}$ & & & 0.782 & 0.59 & 1.26 \\
\hline $\begin{array}{c}\text { Group 4 } \\
\text { (control) }\end{array}$ & & $\mathbf{2 . 6}$ & & $0.00^{*}$ & 3.56 & 1.7 \\
\hline $\begin{array}{c}\text { Group 4 } \\
\text { (control) }\end{array}$ & & 6.07 & $0.00^{*}$ & 7.00 & 5.14 \\
\hline
\end{tabular}

*Mean difference is significant at 0.05 level

$* * \mathrm{CI}=95 \%$ Confidence interval

Table 6:-Intergroup comparison (post hoc analysis) of follow up oral health Attitude.

\begin{tabular}{|c|c|c|c|c|c|c|}
\hline $\begin{array}{c}\text { Variable } \\
\text { (Mean } \\
\text { Difference)KAB }\end{array}$ & $\begin{array}{c}\text { Group 1 } \\
\text { (Mobile) }\end{array}$ & $\begin{array}{c}\text { Group 2 } \\
\text { (e- mail) }\end{array}$ & $\begin{array}{c}\text { Group 3 } \\
\text { (Pamphlet) }\end{array}$ & P value & Minimum & Maximum \\
\hline Group 1 (Mobile) & & 1.84 & & $0.00^{*}$ & 2.52 & 1.17 \\
\hline $\begin{array}{c}\text { Group 1 } \\
\text { (Mobile) }\end{array}$ & & 4.71 & $0.00^{*}$ & 5.39 & 4.03 \\
\hline Group 2(e-mail) & & 2.86 & $0.00^{*}$ & 3.54 & 2.18 \\
\hline Group 4 (control) & \multicolumn{2}{|c|}{0.6} & & $0.002^{*}$ & 2.11 & 0.33 \\
\hline
\end{tabular}




\begin{tabular}{|c|c|c|c|c|c|}
\hline $\begin{array}{l}\text { Group } 4 \\
\text { (control) }\end{array}$ & & 4.09 & $0.00 *$ & 4.98 & 3.20 \\
\hline $\begin{array}{l}\text { Group } 4 \\
\text { (control) }\end{array}$ & 0.62 & & $0.00 *$ & 0.26 & 1.50 \\
\hline
\end{tabular}

*Mean difference is significant at 0.05 level

$* * \mathbf{C I}=95 \%$ Confidence interval

\section{Discussion:-}

The present study demonstrates the feasibility of providing oral health education by employing recent technological advancements in India. The widespread use of technology is an easy to organize school based intervention, exploring new frontiers in dental public health.

Dental health education was provided to mothers using pamphlets (leaflets) or mobile text messages. The messages covered topics that would help the mothers to maintain an optimum oral health for their children and themselves. The topics covered in the pamphlets, e-mail and text messages were dental caries, its etiology and related factors, restriction of sugar exposure for children, tooth brushing methods, importance of fluoride in toothpastes, importance of deciduous and permanent teeth, importance of tongue cleaning, importance of visiting the dentist and information about preventive methods like fluoride gel or varnish applications and pit and fissure sealants (Sharma et al, 2011; Hashemian et al, 2015).

This approach can be effective in improving oral health among children; in particular, in countries with a developing oral health system. In view of the scarce resources and the increasing burden of oral disease in India, a prevention oriented school based intervention would be more advantageous than a curative approach.

For the prevention of major oral health diseases, dental caries and periodontal diseases, it is of utmost importance to maintain a clean mouth. Well-planned and executed oral health promotion programmes could greatly accelerate the decline of the periodontal problems, dental caries etc (Shenoy et al, 2010; Haleem et al, 2012).

Rajesh et al (2008) conducted a study to determine the effect of various high school children. The results revealed that the computer method was found to be most effective in improving oral health knowledge whereas computer method was found to be most effective in improving oral health knowledge method and charts-models improved their plaque and gingival status.

Bannik et al (2012) conducted that adolescents receiving internet based tailored health messaging on their health behaviour and wellbeing had fewer mental health problems and less risky behaviour compared to the control group.

D'cruz et al (2013) reported a significant improvement in the oral hygiene knowledge and practices in groups that utilized audio-visual aids for imparting dental health education. There were significant reductions in the mean plaque and gingival index scores in the experimental groups. However, the control group indicated a significant improvement. The probable explanation for this difference might be that there health education was not provided by any aid used in other groups. Garbin et al(2013)have reported that individual demonstration was most effective in improving oral health knowledge of study subjects. Further studies are needed to confirm the findings of the present study.

The study design prevented 'contamination' and ensured that the responses obtained were due to the intervention. Reinforcement were provided at one two and three months for in the present study. It has been observed in a previous study that reinforcement through repeated sessions resulted in significant improvements in oral health knowledge and attitudes scores (Suprabha et al, 2013).

Handheld devices like mobile phones are generally small, lightweight, handy and portable to provide health education in rural areas of the country where $70 \%$ of the population resides. A small device like mobile phone as basic requirement these days can be used to educate children about oral health. The use of mobile phone was more interactive and lead to increased interest and discussion among the participants. As a public health dentist, it is a 
boon in our hand and can be used for the greater good for the society. The method was seen to be more interactive and interesting keeping the benefits of school children.

The present study viewed in the context of its limitations. Interferences with school curriculum might be a problem, targeting mother during parent teachers meeting was operationally difficult causing attrition. School population consists of different socioeconomic back ground thus compromising the internal validity of the study. Further studies should be conducted to confirm the improvements seen in long term because improved oral hygiene practices in children may exists only during the intervention period.

Oral health education is a powerful tool in improving the oral health knowledge and attitudes, which can lead to better plaque control and subsequent improvement in gingival health. Reinforcements of oral health information is of utmost importance and is the key to success of any oral health education programme.

\section{The Following Conclusion Can be Drawn from the present study:-}

- Utilization of technological tools in health education -learning environment can improve oral health knowledge and attitudes

- Existing technological resources can be effective in improving oral health using less manpower, money and materials; in particular, in countries with a developing oral health system.

- Active involvement of mothers of school children with reinforcement of OHE can improve oral health knowledge and attitude

- Mobile phone method was most effective in improving oral health attitude scores

Widespread use of technology by common man is an inexpensive and easy to organize channel for OHE, exploring new frontiers in Dental Public Health. New developments in technology can be effectively employed in improving oral health using fewer resources, especially in countries with a developing oral health systems. Text messaging has the potential to reach a large number of individuals at a relatively low cost, and may be cost-effective when compared with use of the telephone.

\section{References:-}

1. Patro BK, Ravi Kumar B, Goswami A, Mathur VP, Nongkynrih B. Prevalence of dental caries among adults and elderly in an urban resettlement colony of New Delhi. Indian J Dent Res 2008; 19:95-8 2.

2. Nakre PD. Harikiran AG. Effectiveness of oral health education program: A systematic review. J IntSocPrev Community Dent 2013; 3:103-15.

3. 7th Global Conference on Health Promotion [internet]. World Health Organization. [cited 1 May 2014]. Available from http://www.who.int/healthpromotion/conferences/7gchp/en/

4. Yazdani R, Vehkalahti MM, Nouri M, Murtomaa H. School based education to improve oral cleanliness and gingival health in adolescents in Tehran, Iran. Int J Paediatr Dent. 2009 Jul; 19(4):274-81.

5. Local action creating health promoting schools. WHO information series on school health.[Internet][citedMay1];Availablefrom:http://www.who.int/school_youth_health/media/en/sch_local_actio n_en.pdf

6. Booth ML, Samdal O. Health-promoting schools in Australia: models and measurement. Aust N Z J Public Health. 1997; 21(4 Spec No):365-70.

7. Balappanavar AY, Sardana V, HegdeP.Social Networking and Oral Health Education. International Journal of Scientific Study 2013;01(1):16-9.

8. Mattheos N, Stefanovic N, Apse P, Attstrom R, Buchanan J, Brown P, Camilleri A, Care R, Fabrikant E, Gundersen S, Honkala S, Johnson L, Jonas I, Kavadella A, Moreira J, Peroz I, Perryer DG, Seemann R, Tansy M, Thomas HF, Tsuruta J, Uribe S, Urtane I, Walsh TF, Zimmerman J, Walmsley AD. Potential of information technology in dental education. Eur J Dent Educ 2008; 12 Suppl 1:85-92.

9. Rajesh G, Prasad KV, Mohanty VR, Javali, SB. Effect of various methods of oral health education on oral health status of high school children in Gadag town - randomized control trial. J Indian Assoc Public Health Dent 2008; 11: 41-5.

10. Sharma R, Hebbal M, Ankola A, Murugabupathy V. Mobile-phone text messaging (SMS) for providing oral health education to mothers of preschool children in Belgaum City. Journal of Telemedicine and Telecare 2011; 17: 432-436. 
11. Hashemian TS, Kritz-Silverstein D, Baker R. Text2Floss: The feasibility and acceptability of a text messaging intervention to improve oral health behavior and knowledge. Journal of Public Health Dentistry 2015;75(1):3441.

12. Shenoy RP, Sequeria PS. Effectiveness of school dental education program in improving oral health knowledge and oral hygiene practices and status of 12 -13 year old school children. Indian J Dent Res 2010; 21: 253-9.

13. Haleem A, Siddiqui MI, Khan AA. School-based strategies for oral health education of adolescents - A cluster randomized controlled trial. BMC Oral Health 2012;12(1):54.

14. Bannink R, Joosten-van Zwanenburg E, van de Looij-Jansen P, van As E, Raat H. Evaluation of computer tailored health education ('E-health4Uth') combined with personal counselling ('E-health4Uth+counselling') on adolescents' behaviour and mental health status: design of a three-armed cluster randomized controlled trail. BMC Public Health 2012; 12:1083.

15. D'cruzAM, Aradhaya S. impact of oral health education on oral hygiene knowledge, practices, plaque control and gingival health of 13-15 year old school children in Bangalore city. Int J Dent Hygiene 2013; 11:126-33.

16. Garbin CA, Queiroz AP, Garbin AJ, Moimaz SA, Soares GB. Comparision of methods in oral health education from the perspective of adolescents. Oral health Prev Dent 2013; 11:39-47.

17. Suprabha BS, Rao A, Shenoy R, Khanal S. Utility of knowledge, attitude, and practice survey, and prevalence of dental caries among 11 to 13 year old children in an urban community in India. Global health Action 2013; $6: 10$. 